\title{
Building a Company Step By Step, Chapter 5: Get Out of the Building
}

Jon Eckhardt (University of Wisconsin-Madison)

KEYWORDS: Startups, customer discovery.

EIX is featuring interviews that explore the principles outlined in Steve Blank and Bob Dorf's book, "The Startup Owners Manual: The Step-by-Step Guide for Building a Great Company." (https://www.amazon.com/Startup-Owners-ManualStep-Step/dp/1119690684) This interview with Rachel Carpenter, founder of the financial data company Intrinio(https://www.intrinio.com), focuses on Chapter 5, Get Out of the Building to Test the Problem: Do People Care?

Carpenter, who learned early in her career that she wanted to innovate rather than work for someone else, takes a more relaxed view of the disciplined approach to customer discovery that the book recommends. When she started Intrinio, Carpenter built contacts and leads the old fashioned way: by reaching out to everyone she knew and attending networking events. And her original visions of the customer and which problems needed solving changed profoundly once she started diving into the market. While she believes in the value of testing markets and says she'd embrace more structure to the customer discovery process if she were starting a company today, Carpenter acknowledges that "some things you just need to jump off a cliff with."

\section{Listen}

Link to video

EIX

(https://soundcloud.com/user-876519212-189256831).

Ch5 Rachel Carpenter

(https://soundcloud.com/user-876519212-189256831/c

h5-rachel-carpenter-v1-otter) 